JOURNAL OF NURSING PRACTICE AND EDUCATION VOL. 02 NO. 01, DESEMBER 2021

DOI: $10.34305 /$ JNPE.V2I1.358
Ciptaan disebarluaskan di bawah Lisensi Creative Commons AtribusiNonKomersial-BerbagiSerupa 4.0

\title{
HUBUNGAN PENGETAHUAN REMAJA TENTANG PENDIDIKAN SEKS DENGAN PERILAKU SEKS PRANIKAH PADA REMAJA DI SMK MUTIARA INSANI
}

\author{
Deti Ismayanti, Lela Zakiah,Imas Nurjanah \\ AKBID Prima Husada Bogor \\ deti.ismayanti@gmail.com
}

\begin{abstract}
Abstrak
Perilaku seks pranikah adalah segala tingkah laku yang didorong oleh hasrat seksual baik dengan lawan jenisnya maupun dengan sesama jenis. Salah satu faktor penyebab utamanya yaitu minimnya pengetahuan seks yang benar dan terpadu melalui pendidikan formal maupun non formal.Tujuan penelitian ini adalah untuk mengetahui hubungan pengetahuan remaja tentang pendidikan seks dengan perilaku seks pranikah di SMK Mutiara Insani tahun 2021. Penelitian ini menggunakan Metode observasional analitik dengan pendekatan cross sectional. Sampel yang digunakan total sampling dengan subjek penelitian sejumlah 35 responden terdiri dari siswa SMK Mutiara Insani Kejuruan Multimedia. Alat ukur yang digunakan adalah kuesioner dan analisis dan uji statistik yang digunakan adalah uji chi-square dengan bantuan program SPSS versi 23. Dari penelitian ini yang diperoleh hasil bahwa responden dengan pengetahuan kurang berjumlah 18 orang $(51,4 \%)$ dan pengetahuan baik berjumlah 1 orang $(2,9 \%)$ sedangkan responden perilaku positif berjumlah 22 orang $(62,9 \%)$ dan dengan perilaku baik berjumlah 13 orang (37,1\%). Dari hasil uji statistik Chi-square diperoleh nilai $\rho$ value $0,211<0,05$ maka Ha ditolak yang artinya tidak terdapat hubungan antara pengetahuan pendidikan seks dengan perilaku seks pranikah. Oleh karena itu diharapkan siswa mendapatkan pembelajaran atau penyuluhan tentang dampak dan cara menghindari seks pranikah untuk meningkatkan pengetahuan sehingga menghindari hal tersebut.
\end{abstract}

Kata kunci : Pengetahuan, Perilaku, Seks Pranikah 
JOURNAL OF NURSING PRACTICE AND EDUCATION VOL. 02 No. 01, DESEMBER 2021

DOI: $10.34305 /$ JNPE.V2I1.358
Ciptaan disebarluaskan di bawah Lisensi Creative Commons AtribusiNonKomersial-BerbagiSerupa 4.0 .

Di indonesia dari hasil dari Survei Demografi Dan Kesehatan Indonesia (SDKI) di tahun 2017 menjelaskan bahwa sebelum menikah seorang laki-laki yang beranjak dewasa cenderung lebih sering melakukan seks. Hal ini juga ditunjukkan dengan persentasenya yang mencapai 11,5 persen. (Sahae et al., 2021).

Pada Survei skrinning adiksi pornografi yang dilakukan pada tahun 2017 di daerah ibu kota jakarta menunjukan hasil paparan pornografi yaitu sebesar 96,7 persen sedangkan untuk sisanya setidaknya mengalami adiksi pornografi. Dan untuk di jawa Barat terdapat 2,40\% remaja yang melakukan perilaku seks pranikah (Information \& Seksual, 2021)

Serta survei yang pernah dilakukan oleh Dinas Kesehatan Kabupaten Bogor di tahun 2013 silam menunjukkan hasil bahwa 104 dari 2.516 responden memberikan pengakuan bahwa ia pernah melakukan seks pranikah dalam penelitian ini merupakan siswa yang dikeluarkan dari 25 sekolah di jawa Barat karena pelanggaran hubungan intim di sekolah. Lembaga Pratista Indonesia (LPI) melakukan kajian terhadap remaja yang ada di Bogor dan hasilnya menunjukkan bahwa para remaja tersebut melakukan seks pranikah pertama kali di usia 13 sampai dengan 18 tahun. yang ada di dunia (ASHAR, 2014). 
JOURNAL OF NURSING PRACTICE AND EDUCATION VOL. 02 NO. 01, DESEMBER 2021

DOI: $10.34305 / \mathrm{JNPE} . \mathrm{V} 2 \mathrm{I} 1.358$
Ciptaan disebarluaskan di bawah Lisensi Creative Commons AtribusiNonKomersial-BerbagiSerupa 4.0
Bebasnya pergaulan para remaja ini sehingga mereka dapat melakukan seks pranikah dikarenakan tersedianya akses dan fasilitas untuk melakukan hal tersebut. Mereka akan melakukan seks pranikah tersebut biasanya di dalam kosan, penginapan, atau bahkan di rumah mereka sendiri tanpa adanya pengawasan dari orang tua. (Choirunissa\& Sari, 2017).

Tingginya kejadian hubungan seks pranikah pada remaja menurut berbagai penelitian ada bermacam-macam faktor. Diantaranya adalah adanya dorongan biologis, pemberian fasilitas (termasuk uang) pada remaja secara berlebihan, pergeseran nilai-nilai moral dan etika di masyarakat, serta kemiskinan mendorong terbukanya kesempatan bagi remaja khususnya perempuan untuk dapat melakukan hubungan seks pranikah (Kasim, 2014).

Bebasnya seks pranikah di kalangan remaja ini dikarenakan terjadinya kekeliruan pengetahuan oleh mereka perihal eduksi seks. Hal tersebut membuat timbulnya rasa penasaran yang mendalam dan pada akhirnya mereka akan melakukannya sendiri tanpa berpikir panjang mengenai dampak yang terjadi di masa mendatang. Dan pada saat dampak dari seks pranikah sudah terlihat, mereka cenderung mengalami ketakutan untuk membuat pengakuan kepada orangtuannya. Sehingga mereka memilih untuk menyimpan rahasia tersebut sendiri. (Hasibuan et al., 2014).

\section{Metode}

Jenis penelitian penelitian yang digunakan adalah metode penelitian observasional analitik dengan pendekatan cross sectional.

Penelitian ini menggunakan total sampling dengan subjek penelitian sejumlah 35 responden serta data primer yang digunakan ialah yang diperolehannya secara langsung melalui proses wawancara dan kuesioner Pengolahan data yang dilakukan yaitu memeriksa kelengkapan data dari kuesioner, memasukkan data ke dalam komputer dengan program Microsoft Excel dan Statistical Program for Social Science (SPSS).Analisis data terdiri dari analisis univariat dan bivariat. 
JOURNAL OF NURSING PRACTICE AND EDUCATION VOL. 02 NO. 01, DESEMBER 2021

DOI: $10.34305 / \mathrm{JNPE} . \mathrm{V} 2 \mathrm{I} 1.358$
Ciptaan disebarluaskan di bawah

Lisensi Creative Commons Atribusi-

NonKomersial-BerbagiSerupa 4.0

Hasil

Tabel 1 Distribusi Frekuensi Pengetahuan Remaja Tentang Pendidikan Seks

\begin{tabular}{lll}
\hline Pengetahuan & N & \% \\
\hline Kurang & 18 & 51,4 \\
Cukup & 16 & 45,7 \\
Baik & 1 & 2,9 \\
\hline Total & $\mathbf{3 5}$ & $\mathbf{1 0 0 . 0}$ \\
\hline
\end{tabular}

Sumber : Data Primer Tahun 2021

Tabel 2 Distribusi Frekuensi Perilaku Seks Pranikah

\begin{tabular}{lll}
\hline Perilaku & N & \% \\
\hline Negatif & 13 & 37,1 \\
Positif & 22 & 62,9 \\
\hline Total & 35 & 100.0 \\
\hline
\end{tabular}

Sumber : Data Primer Tahun 2021

Tabel 3 Hubungan Pengetahuan Pendidikan Seks Dengan Perilaku Seks Pranikah

\begin{tabular}{|c|c|c|c|c|c|c|c|c|}
\hline \multirow{3}{*}{ Pengetahuan } & \multicolumn{4}{|c|}{ Perilaku } & \multirow{2}{*}{\multicolumn{2}{|c|}{ Total }} & \multirow{3}{*}{$P$ value } & \multirow{3}{*}{ OR } \\
\hline & \multicolumn{2}{|c|}{ Positif } & \multicolumn{2}{|c|}{ Negatif } & & & & \\
\hline & $\mathbf{N}$ & $\%$ & $n$ & $\%$ & $\mathbf{N}$ & $\%$ & & \\
\hline Kurang & 4 & 11,8 & 12 & 34,3 & 16 & 45,7 & & \\
\hline Cukup & 8 & 22,9 & 10 & 28,6 & 15 & 51,4 & 0,211 & 336 \\
\hline Baik & 1 & 2,9 & 0 & 0 & 1 & 2,9 & & \\
\hline Total & 13 & 37,1 & 22 & 62,9 & 35 & 100,0 & & \\
\hline
\end{tabular}

\section{Pembahasan}

Analisis Univariat

Hasil penelitian dari responden 35 orang dapat diketahui bahwa responden paling tertinggi dengan pengetahuan kurang berjumlah 18 orang $(51,4 \%)$ dan sedangkan responden yang paling terendah dengan pengetahuan baik berjumlah 1 orang $(2,9 \%)$.

Secara umum pendidikan seks memberikan informasi yang jelas dan akurat tentang masalah seksual seseorang. termasuk proses kehamilan dari hamil sampai melahirkan perilaku seksual hubungan seksual dan aspek kesehatan, psikologi, dan masyarakat Isu pendidikan seks serta harus dikaitkan dengan norma sosial (Saputra, 2016)

Dari hasil penelitian ini terdapat perbedaan dengan penelitian sebelumnya yang dilakukan oleh Egy Pratama (2014)dengan judul yang sama serta jumlah responden 136 orang Dari hasil analisa data didapatkan bahwa tingkat pengetahuan responden bervariasi, dimana sebagian besar responden $(84,6 \%)$ memiliki 
JOURNAL OF NURSING PRACTICE AND EDUCATION VOL. 02 No. 01, DESEMBER 2021

DOI: $10.34305 / \mathrm{JNPE} . \mathrm{V} 2 \mathrm{I} 1.358$
Ciptaan disebarluaskan di bawah Lisensi Creative Commons AtribusiNonKomersial-BerbagiSerupa 4.0 . pengetahuan baik, kemudian sebagian kecil responden $(15.4 \%)$ memiliki pengetahuan cukup, dan tidak satupun responden memiliki pengetahuan kurang.(Pratama et al., 2014).

Dari hasil penelitian menggunakan analisa univariat dengan 35 sampel, dapat diketahui bahwa responden paling tertinggi dengan perilaku Positif berjumlah 22 orang $(62,9 \%)$ dan sedangkan responden paling rendah dengan perilaku baik berjumlah 13 orang $(37,1 \%)$.

Perilaku seksual adalah segala tingkah laku yang didorong oleh hasrat seksual, baik dengan lawan jenisnya maupun dengan sesama jenis. Faktor yang dapat mempengaruhi perilaku seksual pranikah remaja adalah teman sebaya, aspek - aspek kesehatan reproduksi, sikap terhadap layanan kesehatan seksual dan reproduksi, perilaku, kerentanan yang dirasakan terhadap resiko, kesehatan reproduksi, gaya hidup, pengendalian diri, aktivitas sosial, rasa percaya diri, usia, status perkawinan, sosial budaya, nilai dan norma sebagai pendukung sosial untuk perilaku tertentu. (Putri, 2012)

Dari hasil penelitian ini terdapat perbedaan dengan penelitian sebelumnya yang dilakukan oleh Egy Pratama (2014) dengan judul yang sama serta memiliki kategori perilaku seks pranikah pada remaja, terdiri dari perilaku seks yang tidak berisiko dan perilaku seks yang beresiko yaitu. Dari hasil analisa data didapatkan bahwa dari 136 responden sebagian besar responden $(86 \%)$ berperilaku seks tidak beresiko, dan sebagian kecil responden (14 \%) berperilaku seks yang beresiko (Pratama, et al., 2014)

Analisis Bivariat

Hasil penelitian dari 35 responden yang didapatkan responden memiliki hubungan pengetahuan kurang tentang pendidkan seks dengan perilaku positif terdapat 4 orang $(11,8 \%)$ dan hubungan pengetahuan cukup tentang pendidikan seks dengan perilaku positif terdapat 8 orang (22,9\%) sedangkan hubungan pengetahuan baik tentang pendidikan seks dengan perilaku positif terdapat 1 orang $(2,9 \%)$. Dari hasil uji statistik Chi-square diperoleh nilai $\rho$ value $0,211<0,05$ maka Ha ditolak yang artinya tidak terdapat hubungan antara pengetahuan pendidikan seks dengan perilaku seks pranikah. Selanjutnya nilai Odd Ratio dalam penelitian ini didapatkan 336.

Menurut teori Kumalasari (2012), pada umumnya orang menganggap bahwa pendidikan seks hanya berisi tentang 
JOURNAL OF NURSING PRACTICE AND EDUCATION VOL. 02 No. 01, DESEMBER 2021

DOI: $10.34305 / \mathrm{JNPE} . \mathrm{V} 2 \mathrm{I} 1.358$
Ciptaan disebarluaskan di bawah Lisensi Creative Commons AtribusiNonKomersial-BerbagiSerupa 4.0 . pemberian informasi alat kelamin dan berbagai macam posisi dalam berhubungan seks sehingga para orangtua sangat merasa khawatir dengan anak mereka. Akan tetapi, dengan memberikan pendidikan seks pada remaja seperti perubahan yang terjadi pada diri mereka untuk menjadi dewasa, bahaya berhubungan seksual akan membantu mereka untuk menghindari dan tidak melakukan hubungan seksual (Muarifah et al.,2019)

Dari hasil penelitian ini terdapat perbedaan dengan penelitian sebelumnya yang dilakukan oleh oleh Esti Widiani (2017) di SMA Kristen Setia Budi Malang dengan mengambil sampel sebanyak 58 siswa, didapatkan hasil bahwa sebagian besar responden pengetahuan seks yang tergolong baik dengan hasil 94,83\%, sedangkan untuk perilaku seksual mendapatkan hasil 58,62\%. Hasil uji spearman Rank didapatkan hasil nilai sig (2-tailed) sebesar $0,000<0,05$ yang artinya ada hubungan yang signifikan antara tingkat pengetahuan seks dengan perilaku seksual (Muarifah et al., 2019)

\section{Kesimpulan}

Berdasarkan hasil penelitian yang dilakukan di SMK Mutiara Insani tahun 2021, dapat disimpulkan bahwa tidak terdapat hubungan yang signifikan antara pendidikan seks dengan perilaku seks pranikah pada remaja.

\section{Saran}

Diharapkan pihak sekolah dan orang tua lebih memiliki pendekatan serta mengedukasi remaja terkait pendidikan seks pranikah dan remaja dapat mempelajari memahami agar dapat terhindar dari perilaku seks yang menyimpang.

\section{Daftar Pustaka}

Ashar, R. (2014). Hubungan Pengetahuan Dan Sikap Tentang Kesehatan Reproduksi Dengan Perilaku Seks Pranikah Pada Remaja Rasyida Ashar STIKes Surya Mitra Husada Kediri.

Choirunissa, R., \& Sari, D. K. (2017). Faktor-Faktor Yang Berhubungan Dengan Perilaku Seksual Remaja Di Desa Mega Mendung Kecamatan Mega Mendung Kabupaten Bogor Provinsi Jawa Barat. Jurnal Ilmu Dan Budaya, 40(57), 6587-6598.

Hasibuan, R., Dewi, Y. I., \& Huda, N. (2014). Faktor-Faktor Yang Mempengaruhi Kejadian Seks Pranikah Pada Remaja Putri Di SMAN 1 Pagai Utara Selatan Kabupaten Kepulauan Mentawai Roma [Universitas Riau]. https://media.neliti.com/media/publica tions/186376-ID-faktor-faktor-yangmempengaruhi-kejadian.pdf 
JOURNAL OF NURSING PRACTICE AND EDUCATION VOL. 02 No. 01, DESEMBER 2021

DOI: $10.34305 /$ JNPE.V2I1.358
Ciptaan disebarluaskan di bawah Lisensi Creative Commons AtribusiNonKomersial-BerbagiSerupa 4.0 .

Saputra, M. I. (2016). Pendidikan Seks Bagi Remaja Menurut Abdullah Nasih Ulwan. Jurnal Pendidikan Islam, 7, 143-156.

Kasim, F. (2014).Dampak Perilaku Seks Berisiko Terhadap Kesehatan Reproduksi Dan Upaya Penanganannya (Studi Tentang Perilaku Seks Berisiko Pada Usia Muda Di Aceh. Jurnal Studi Pemuda, 3(1), 39-38. https://jurnal.ugm.ac.id/jurnalpemuda/ article/download/32037/19361

Muarifah, A., Danny Soesilo, T., \& Tagela, U. (2019). Hubungan Pengetahuan Tentang Pendidikan Seks Dengan Perilaku Seksual Remaja. Journal for Lesson and Learning Studies, 2(1), 19.

https://doi.org/https://doi.org/10.23887 /jlls.v2i1.17314

Pratama, E., Hayati, S., \& Supriatin, E. (2014). Hubungan Pengetahuan Remaja Tentang Pendidikan Seks dengan Perilaku Seks Pranikah pada Remaja di SMA Z Kota Bandung. jurnal Ilmu Keperawatan, II(2), 149156.

http://ejournal.bsi.ac.id/assets/files/Jur nal_Keperawatan_Vol._II_No_2_Sept ember_2014_Egy_Pratama,_Sri_Hayat i,_Eva_Supriatin_149-156_.pdf

Putri, A. F. (2012). Faktor-Faktor Yang Mempengaruhi Seks Pranikah Pada Remaja Sma Di Rengat Kabupaten Indragiri Hulu.

Sahae, E., Tucunan, A. A. T., K. F. (2021). Dengan Perilaku Seksual Pranikah Pada Remaja Di SMK Negeri 1. 10(1), 153-164. 